\title{
The use of long-acting Aripiprazole in a multi-center, prospective, uncontrolled, open-label, cohort study in Germany: a report on global assessment of functioning and the WHO wellbeing index
}

Daniel Schöttle ${ }^{1 *}$ (D), Wolfgang Janetzky ${ }^{2}$, Daniel Luedecke ${ }^{1}$, Elmar Beck ${ }^{3}$, Christoph U. Correll ${ }^{4,5,6}$ and Klaus Wiedemann ${ }^{1}$

\begin{abstract}
Background: In this non-interventional study, the functionality and well-being of patients with schizophrenia with aripiprazole once-monthly (AOM) was evaluated under real-life conditions in a naturalistic population.

Methods: This non-interventional, prospective, multicenter 6-month study included 242 predominantly symptomatically stable patients (mean age $43.1 \pm 15.1$ years, 55\% male) who switched their treatment to AOM after 9.7 $( \pm 22.3)$ months of oral treatment. Outcome parameters included functionality (Global Assessment of Functioning, GAF), patient's wellbeing (WHO-5 Well-Being Index, WHO-5), and both patient's and clinician's assessment of efficacy and tolerability of AOM. Treatment emergent adverse events (TRAE) were also recorded.
\end{abstract}

Results: At baseline, the mean GAF score was 47.0 ( \pm 13.9$)$, indicating that patients experienced serious impairment in functioning. A continuous increase to $60.2( \pm 17.0)$ during treatment was found, with a robust and significant increase already after 4 weeks. At study start, patients reported diminished wellbeing, with a mean score of $10.6( \pm 5.6)$ on the WHO-5 scale. During treatment, patient wellbeing increased continuously with strong and significant improvements even after 4 weeks and an overall improvement of $4.8( \pm 6.9)$ over the course of 6 months with an endpoint of 15.4 ( \pm 5.5). Stratification of these results showed that more pronounced effects were achieved in younger patients $\leq 35$ years $(p<0.05$ for GAF). The effectiveness and tolerability of AOM was rated good/very good by most patients ( 89.2 and 93.7\%) and physicians (91.4 and 96.8\%). Only few TRAEs occurred.

Conclusions: Our results show a significant positive effect after initiation of AOM treatment in predominantly stable patients with schizophrenia on their functioning and wellbeing, which was even more pronounced in patients aged $\leq 35$ years, thereby supporting previous randomized controlled findings under routine conditions in clinical practice.

Keywords: Long-acting injectable, LAl, Naturalistic, Schizophrenia, Schizoaffective, Patient perspective

\footnotetext{
* Correspondence: d.schoettle@uke.de

${ }^{1}$ Klinik für Psychiatrie und Psychotherapie, Zentrum für Psychosoziale

Medizin, Universitätsklinikum Hamburg-Eppendorf, Martinistrasse 52, 20246

Hamburg, Germany

Full list of author information is available at the end of the article
}

(c) The Author(s). 2020 Open Access This article is distributed under the terms of the Creative Commons Attribution 4.0 International License (http://creativecommons.org/licenses/by/4.0/), which permits unrestricted use, distribution, and reproduction in any medium, provided you give appropriate credit to the original author(s) and the source, provide a link to the Creative Commons license, and indicate if changes were made. The Creative Commons Public Domain Dedication waiver (http://creativecommons.org/publicdomain/zero/1.0/) applies to the data made available in this article, unless otherwise stated. 


\section{Background}

Schizophrenia is a mental disorder starting in adolescence, that severely impairs patients` functioning and diminishes their quality of life as well as their general wellbeing [1]. In general, schizophrenia is characterized by recurring episodes characterized by positive symptoms, such as hallucinations and thought disorders, as well as negative symptoms, like blunted affect and avolition. Treatment of these negative symptoms is challenging, as they may persist even after remission from an acute episode and as they can have a further negative impact on quality of life and general wellbeing. Therefore, patients may not regain their previous level of functioning and quality of life $[2,3]$. For this reason, it is highly important to intervene early after onset of the disease to prevent relapses and restore functional, cognitive, and affective capabilities [4]. For relapse prevention, adherence to pharmacological and psychosocial treatment is critical. However, independent of having a first or having had multiple psychotic episodes, nonadherence rates in patients with schizophrenia are high [5], and the reasons for nonadherence are complex [6-8]. Adherence to pharmacological treatment may be improved when long-acting injectables (LAIs) are used, which has been mainly demonstrated under real life conditions [9-14]. Aripiprazole oncemonthly (AOM) is an atypical LAI that was shown to elicit clinically relevant and lasting improvements in the patients quality of life in the QUALIFY study $[15,16]$, accompanied by improvements in functioning and ability to work [17]. Furthermore, pre-specified exploratory analyses of age groups showed that younger patients ( $\leq 35$ years of age) benefited even more from the treatment [15]. Furthermore, patient functioning and quality of life were superior during AOM treatment compared with oral standard-of-care in a naturalistic study [18].

The present non-interventional study in a naturalistic setting under routine treatment conditions with a heterogenous patient sample was designed to confirm the results of the previous randomized controlled clinical studies [19-21], which were conducted in a more homogenous population of patients. As the physician's view on the severity of the disease and improvement of psychosocial functioning and quality of life may differ from the patients perspective [22, 23], it is important to assess both perspectives by collecting information from both groups. How patients experience a beneficial effect not only regarding symptomatic improvement and low rates of side-effects, but also how they evaluate subjectively important domains, such as psychosocial functioning and their general quality of life, becomes ever more important with increasing therapy duration as it impacts the will to adhere to and continue with the treatment [24-26].

In a previous study in the same patient cohort, effectiveness measurements of psychopathology (Brief Psychiatric Rating Scale, BPRS) and severity of illness scales
(Clinical Global Impression-Severity, CGI-S and Clinical Global Impression-Improvement, CGI-I), were analyzed and discussed [27]. Briefly, at baseline, most of the patients were markedly ill and had predominantly stable symptomatology for an average of 5.9 months (SD: 18.2), with 91 patients $(39.2 \%)$ being stable for $<1$ month and $28(12.1 \%)$ not being stable at all. They had a mean global BPRS value of 54.1 (SD 15.6), and a mean CGI-S value of 4.8 (SD 0.8). The reduction in global BPRS was - 13.8 (SD: $16.0 ; p<0.001$ ) at follow-up. The proportion of patients with high (worse) CGI-S scores decreased $(\mathrm{p}<0.001)$, and the proportion of patients with low scores increased significantly $(p<0.001)$. All together, $35.3 \%$ of the patients improved by one grade on the CGI-S score (in Fig. 6 of the original publication [27], a portion of $38.3 \%$ was mistakenly given); $24.3 \%$ of the patients improved by 2 grades or even more.

In this multicenter, prospective, non-interventional study, 242 patients with schizophrenia were treated with AOM and monitored over the course of 6 months. The treating clinicians were asked to estimate the patient's level of functioning on the Global Assessment of Functioning (GAF) scale. Patient wellbeing was assessed using the WHO-5 wellbeing index. Efficacy and tolerability of AOM was rated by the patients as well as the clinicians. Thus, we hypothesized that 6 months of AOM treatment would significantly improve functional status and wellbeing of patients receiving usual-care based AOM treatment.

\section{Methods \\ Design}

This multicenter, prospective, 6-month, uncontrolled, open-label, cohort study was designed and conducted in a naturalistic setting according to the German Medicinal Product Act and approved by the Freiburg ethics commission international (Approval number: 014/1336).

Data were collected from 75 German centers, including outpatient clinics and resident physicians, between July 2014 and March 2016. The choice of treatment with AOM was independent from the inclusion in the study cohort.

Patients were seen about every 4 weeks $(-2 /+5$ days $)$ at seven time points during the study (T0-T6, Fig. 1). Data were collected using patient and clinician questionnaires at each time point.

\section{Patients}

Inclusion criteria for patients were: age $\geq 18$ years, diagnosis of schizophrenia (F20.X) according to ICD-10, and treatment with AOM according to prescribing information on an outpatient basis. The choice to switch from oral aripiprazole to treatment with AOM was made prior to inclusion in the cohort. Patients gave written consent to participate. 


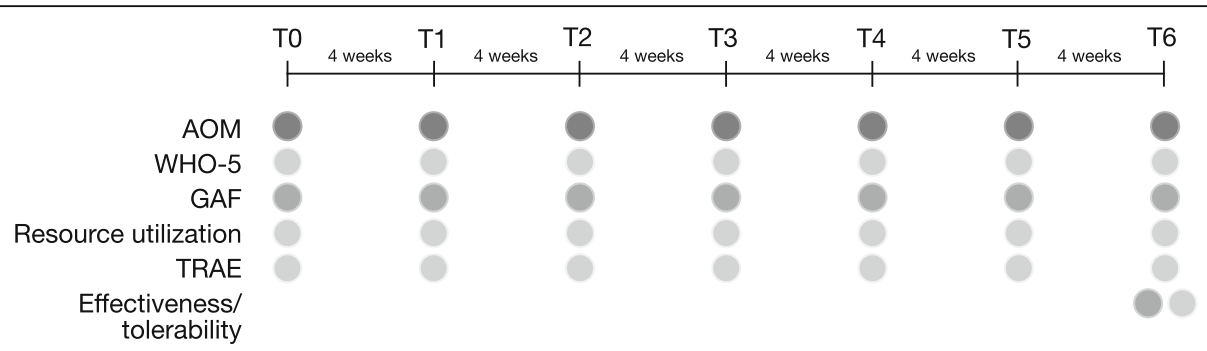

Fig. 1 Study design. Patients were treated with AOM at seven time points (T0-T6) in four-week intervals. Data was collected at the time points indicated. Light gray color indicates statements by the patient, dark gray color statements by the physician. AOM, Aripiprazole once-monthly; WHO-5, WHO-5 wellbeing index; GAF, Global Assessment of Functioning; TRAE, treatment related adverse events

Exclusion criteria were contraindication to AOM, being a member or being related to a member of the study staff, pregnancy, planning a pregnancy, nursing, or probable reluctance to adhere to the monitoring plan (evaluated by the treating physician).

Patients were regarded as clinically stable when having no pronounced fluctuations in their symptoms and when taking their oral medication at a stable dosage for several weeks. Being stable was not clearly defined, but decided by the prescribing clinician on an individual basis.

\section{Assessments}

In the Global Assessment of Functioning (GAF) scale, physicians are asked to give the patient's overall functioning as a single value between 100 (excellent functionality) and 1 (persistent danger of severely hurting self or others or persistent inability to maintain minimal personal hygiene or serious suicidal act with clear expectation of death). Possibly clinically relevant changes were defined as 4, 10 or 12 points, according to Amri et al. [28].

The WHO-5 wellbeing index is a self-rating short questionnaire comprising five items to assess a patient's wellbeing, balancing the wanted and unwanted effects of treatments [29]. It contains statements about the patient's wellbeing, and the patients' estimate of the amount of time this was true during the last 2 weeks between 0 (at no time) and 5 (all of the time), yielding a total score of $0-25$. A score of $\leq 13$ is considered indicative of being at risk for depression [29]. Patients completed this questionnaire at every other visit (T0-T6). A change of $\geq 10 \%$ (here corresponding to 2.5 points) is considered clinically relevant [29].

The effectiveness and tolerability of AOM treatment was rated by both clinicians and patients on a fourpoint Likert scale ranging from "very good", "good", "moderate" to "poor".

Adverse events were reported by the patients at every other visit and categorized by the treating clinicians as treatment-related (TRAE) or unrelated events.

Other rating scales also used in the same study, but not presented here, are discussed elsewhere [27].

\section{Statistical analysis}

Due to the non-interventional design of the study, all data were collected as descriptive statistical values. Missing values were complemented by the Last Observation Carried Forward (LOCF) method if there was a value for T0 and at least one other time point. Data were processed using $\mathrm{SAS}^{\mathrm{Tm}}$ software. No statistical hypotheses were formulated, and statistical tests were exploratory. The Wilcoxon Signed-Rank test was used for paired samples, and the Wilcoxon's rank-sum test for independent samples. Changes in marginal distributions in contingency tables of categorical outcomes were analyzed using Bhapkar's test [30], and proportions within one group of patients were analyzed with the binomial test. Fisher's exact test was used to compare proportions between groups of patients. Subgroup comparisons by age group were covaried using a linear regression analysis with backward selection of effects for variables that differed significantly between the two age groups at baseline at $p<0.05$ (see Table 1). All tests were two-sided with alpha $=0.05$, without correction for multiple testing.

\section{Results}

Altogether, 278 patients were reported by physicians as potential study participants. 243 patients $(87.4 \%)$ were included in the study cohort. One patient was excluded from the analysis because he did not receive any AOM injections. Patient baseline demographics and clinical characteristics are presented in Table 1. At the time of admission, the GAF score was $47.0( \pm 13.9)$, indicating that patients had on average serious symptoms or serious impairment in social, occupational, or school functioning. The patients reported a mean value of $10.6( \pm$ 5.6) on the WHO-5 wellbeing index. Thus, the patient's wellbeing was below average (in the general population in Germany, scores of 15-18 are the norm) and that they were at risk of depression, considering a cutoff value of 13 [29]. Altogether 15 patients (6.2\%) dropped out during the 6-month observation period and the mean study duration was $5.4 \pm 1.0$ months. 
Table 1 Patient baseline demographics

\begin{tabular}{|c|c|c|c|c|}
\hline & All patients $(n=242)$ & $\begin{array}{l}\text { Patients } \leq 35 \\
\text { years }(n=89)\end{array}$ & $\begin{array}{l}\text { Patients }>35 \\
\text { years }(n=153)\end{array}$ & $\begin{array}{l}p \text { value for comparison } \\
\text { of age groups }\end{array}$ \\
\hline Age, years (SD) & $43.1(15.1)$ & $28.8(4.3)$ & $51.3(12.7)$ & $<0.0001^{a}$ \\
\hline Sex, male, n (\%) & $133(55.0)$ & $57(64.0)$ & $76(49.7)$ & $0.0328^{b}$ \\
\hline $\begin{array}{l}\text { Family status, married } \\
\text { or in a relationship, } \mathrm{n}(\%)\end{array}$ & $53(22.0)$ & $13(14.8)$ & $40(26.1)$ & $0.0520^{\mathrm{b}}$ \\
\hline Employment status, n (\%) & & & & $<0.0001^{b}$ \\
\hline Employed & $43(18.0)$ & $23(26.4)$ & $20(13.2)$ & \\
\hline Unemployed & $73(30.5)$ & $36(41.4)$ & $37(24.3)$ & \\
\hline Annuitant & $99(41.4)$ & $13(14.9)$ & $86(56.6)$ & \\
\hline Housewife/househusband & $11(4.6)$ & $2(2.3)$ & $9(5.9)$ & \\
\hline In school/education/re-education & $13(5.4)$ & $13(15.0)$ & $0(0.0)$ & \\
\hline $\begin{array}{l}\text { Duration of untreated psychosis, } \\
\text { mean (SD), years }\end{array}$ & $1.2(8.0)$ & $1.4(3.2)$ & $1.0(9.8)$ & $0.7719^{a}$ \\
\hline $\begin{array}{l}\text { Age at diagnosis, mean (SD), } \\
\text { years }\end{array}$ & $30.9(13.0)$ & $23.0(4.3)$ & $35.3(14.2)$ & $<0.0001^{\mathrm{a}}$ \\
\hline Time of diagnosis, n (\%) & & & & $<0.0001^{\mathrm{b}}$ \\
\hline$\leq 5$ years & $78(32.4)$ & $47(53.4)$ & $31(20.3)$ & \\
\hline$>5$ years & $163(67.6)$ & $41(46.6)$ & $122(79.7)$ & \\
\hline Number of illness episodes, n (\%) & & & & $0.0002^{\mathrm{b}}$ \\
\hline$\leq 5$ episodes & $\begin{array}{l}137(57.1) \text {; } 19 \text { (7.9) of which with } \\
\text { first episode of schizophrenia }\end{array}$ & $64(72.7)$ & $73(48.0)$ & \\
\hline$>5$ episodes & $103(42.9)$ & $24(27.3)$ & $79(52.0)$ & \\
\hline BMl, mean (SD), $\mathrm{kg} / \mathrm{m}^{2}$ & $29.3(6.9)$ & $28.6(7.3)$ & $29.7(6.6)$ & $0.2381^{\mathrm{a}}$ \\
\hline BPRS at baseline, mean (SD) & $54.1(15.6)(n=228, \mathrm{FAS})$ & $53.0(16.1)(n=88$, all values $)$ & $\begin{array}{l}53.7(15.9)(n=151 \\
\text { all values) }\end{array}$ & $0.7608^{a}$ \\
\hline CGI-S at baseline, mean (SD) & $4.8(0.8)(n=235$, FAS $)$ & $4.7(0.9)(n=89$, all values) & $\begin{array}{l}4.8(0.8)(n=153, \\
\text { all values) }\end{array}$ & $\mathrm{n} / \mathrm{a}$ \\
\hline WHO-5 at baseline, mean (SD) & $10.6(5.6)(n=235$, FAS $)$ & $11.1(5.7)(n=88$, all values $)$ & $\begin{array}{l}10.5(5.7)(n=150 \\
\text { all values) }\end{array}$ & $\mathrm{n} / \mathrm{a}$ \\
\hline GAF at baseline, mean (SD) & $47.0(13.9)(n=235$, FAS $)$ & 49.9 (13.1) ( $n=88$, all values) & $\begin{array}{l}45.6(14.6)(n=152, \\
\text { all values) }\end{array}$ & $\mathrm{n} / \mathrm{a}$ \\
\hline
\end{tabular}

${ }^{\mathrm{a}} \mathrm{t}$-Test; ${ }^{\mathrm{b}}$ Fisher's Exact Test; BMI Body Mass Index; FAS Full Analysis Set; GAF Global Assessment of Functioning; WHO World Health Organization; SD Standard deviation

Where percentages do not add up to $100 \%$, data were missing for some patients. n/a: not available

\section{Patient functioning (GAF)}

The overall patient functioning according to the GAF scale increased significantly during the observational period by 13.2 (SD 16.1), reaching $60.2( \pm 17.0)$ (Fig. 2). We found a continuous increase of values over treatment time. Altogether, 180 patients (76.6\%) improved according to the GAF scale during the study, 35 (14.9\%) remained unchanged, and 20 (8.5\%) worsened. In total, 100 patients (42.6\%) improved by $\geq 12$ points, 130 (55.3\%) improved by $\geq 10$ points, and $166(70.6 \%)$ by $\geq 4$ points, representing possible criteria of clinically relevant changes [28].

In younger patients $\leq 35$ years, the GAF score increased by 16.4 points (SD 18.3) on the GAF scale between T0 and T6. In contrast, patients $>35$ years old increased only by 11.4 points (SD 14.4) (Fig. 3). The differences between the groups were statistically significant at $\mathrm{T} 1$,
T4, T5 and T6 (Wilcoxon Two-Sample test, T1: $p=$ 0.0092, T4: $p=0.0429$, T5: $p=0.0459$, T6: $p=0.0222$ ). Moreover, $80.2 \%$ of the patients $\leq 35$ years old improved during treatment, $12.8 \%$ remained unchanged, and $7.0 \%$ worsened. Regarding patients $>35$ years old, $74.5 \%$ improved, $16.1 \%$ remained unchanged, and $9.4 \%$ worsened. Responders, defined as patients who improved by $\geq 4$, $\geq 10$, or $\geq 12$ points, were included $77.9,67.4 \%$, or $54.7 \%$ of the younger vs. $66.4,48.3 \%$, or $35.6 \%$ of the older patients, respectively.

\section{Patient wellbeing (WHO-5)}

Patient wellbeing increased significantly by 4.8 points (SD 6.9) on the WHO-5 index (Fig. 4), reaching a mean of $15.4 \pm 5.5$ points at $\mathrm{T} 6$, a level that is comparable to the general population [29]. During the course of treatment, 


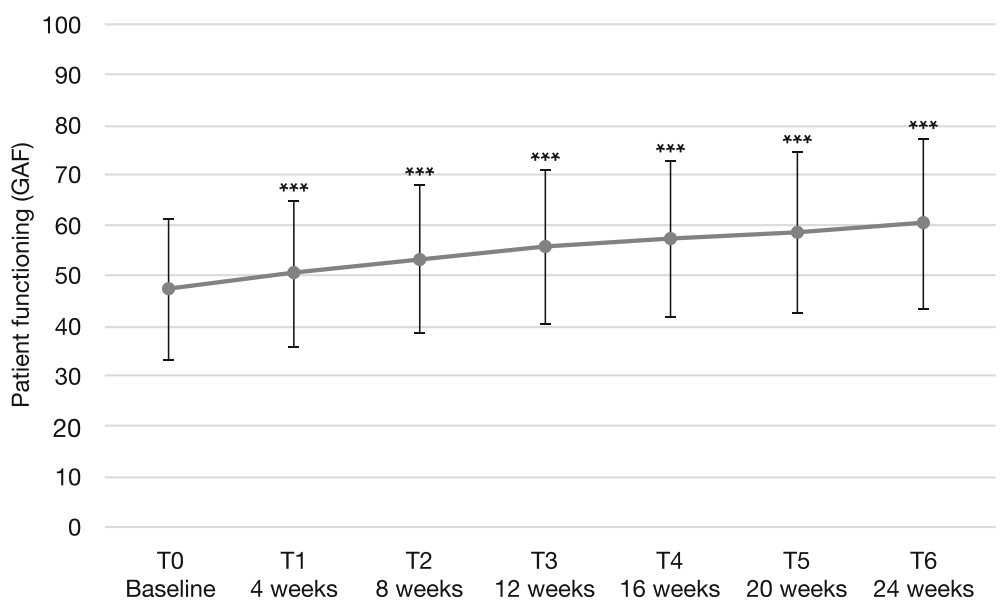

Fig. 2 Patient functioning according to GAF scale. Error bars represent standard deviations. ${ }^{* *}$ significant for each assessment versus baseline, $p<0.001$

there was a continuous increase of the WHO-5 index values. The most prominent improvement was achieved during the first 4 weeks of the study. Altogether, 183 patients (77.9\%) had improved wellbeing indices, 13 (5.5\%) remained unchanged, and 39 (16.6\%) had decreased wellbeing indices during the study.

In younger patients $\leq 35$ years, there was an increase of 5.6 points in the wellbeing index (SD 7.4) between T0 and T6 (Fig. 5). In contrast, patients $>35$ years old increased only by 4.4 points (SD 6.7). Furthermore, $81.4 \%$ of the younger patients had improved values at the end of the study, compared to $75.8 \%$ of the older patients. These differences were not statistically significant.
Regarding the individual items of the wellbeing index, the improvements across the items were similar (Fig. 6), with about a 1-point difference between baseline and follow up in each item. Again, there was a tendency for younger patients $\leq 35$ years to experience greater improvements.

\section{Effectiveness and tolerability}

The effectiveness of AOM treatment was rated to be very good or good by $42.5 \%$ or $48.9 \%$ of the treating physicians, respectively (Fig. 7). The patients rated the effectiveness as very good in $35.9 \%$ and as good in $53.4 \%$ of the cases. Only $2.3 \%$ of the physicians and $2.7 \%$ of the patients gave a

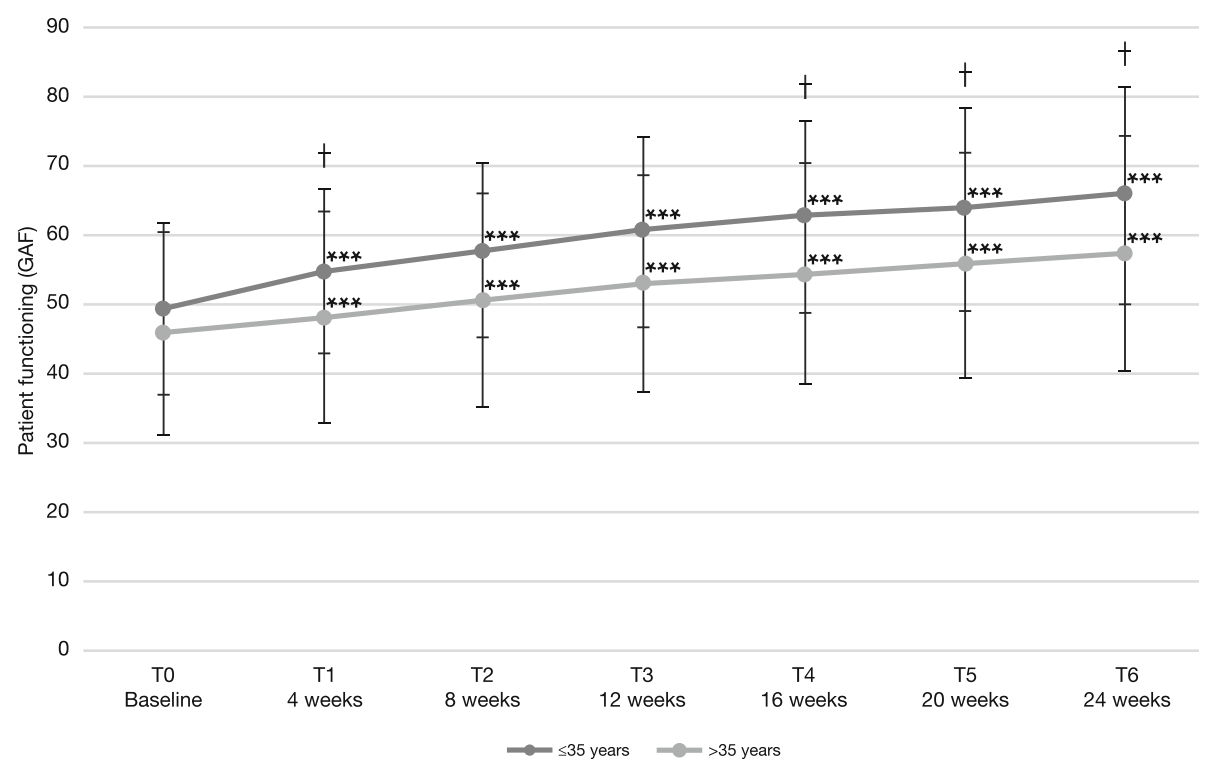

Fig. 3 Patient functioning according to the GAF scale, stratified by age. Error bars represent standard deviations. At all visits, changes for both groups were significant compared to baseline (*** $p<0.001$ ). Differences between groups were significant at $T 1, T 4, T 5$, and $T 6 ; T, p<0.05$ 


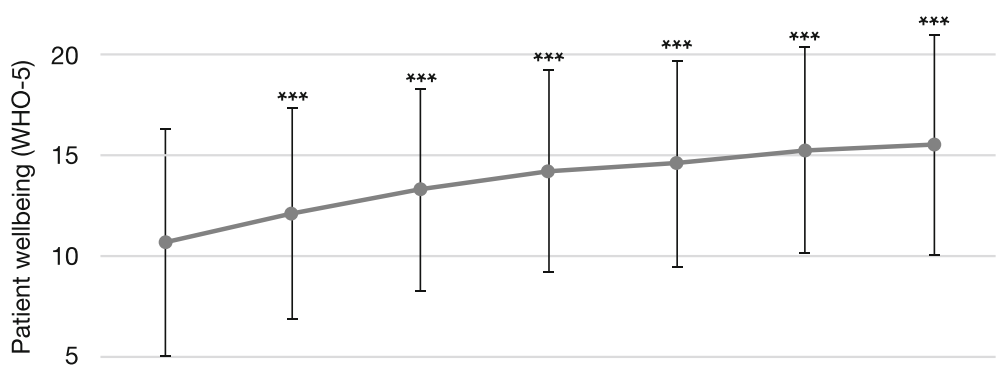

0

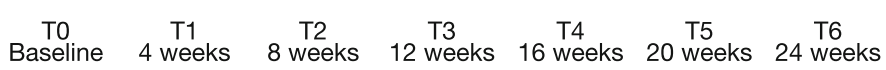

Fig. 4 Patient wellbeing according to the WHO-5 wellbeing index. Error bars represent standard deviations. *** significant for each assessment versus baseline, $p<0.001$

"poor" rating. Differences in patient and physician ratings of AOM effectiveness were not statistically significant.

The tolerability of AOM treatment was rated as very good by $59.4 \%$ of the treating physicians, $37.4 \%$ rated it as good. $45.1 \%$ of the patients rated AOM tolerability as very good and $48.7 \%$ as good. Only $1.4 \%$ of the physicians and $2.3 \%$ of the patients thought that AOM tolerability was poor. The differences in patient and physician ratings of AOM tolerability were statistically significant $(p<0.001)$.

\section{Reasons to switch to AOM treatment}

Up to five reasons for switching the therapy to AOM were stated. The most frequent reasons reported by the treating physicians were assurance of compliance/adherence/drug intake $(117,48.4 \%)$, better/good tolerability $(41,16.9 \%)$, patient choice $(33,13.6 \%)$, better/good efficacy (29,
$12.0 \%)$, and ease of administration (22, 9.1\%, all based on total population).

\section{Continuation of therapy with AOM}

After study completion, 200 patients (82.6\%) continued their therapy with AOM, 24 (9.9\%) discontinued it (data were missing for 18 patients). Reasons for discontinuation included patient choice $(9,3.7 \%)$, lack of efficacy $(7,2.9 \%)$, adverse drug reaction $(6,2.5 \%)$ and change to inpatient drug addiction therapy $(1,0.4 \%)$. One patient dropped out one patient moved away ( $0.4 \%$ each, all based on total population, one patient gave two reasons for discontinuation).

\section{Adverse events}

Patients reported a total of 153 adverse events (AE) during the study, 133 of which were deemed as probably or possibly treatment related (TRAE) by the clinicians. All

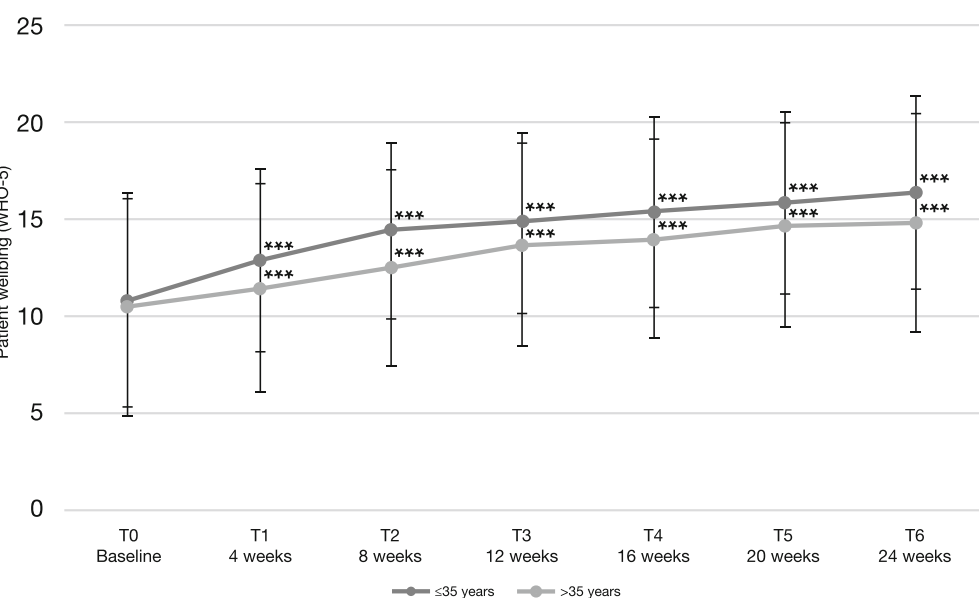

Fig. 5 Patient wellbeing according to the WHO-5 wellbeing index, stratified by age. Error bars represent standard deviations. ${ }^{* * *}$ significant for each assessment versus baseline, $p<0.001$. Between-group differences were not significant 


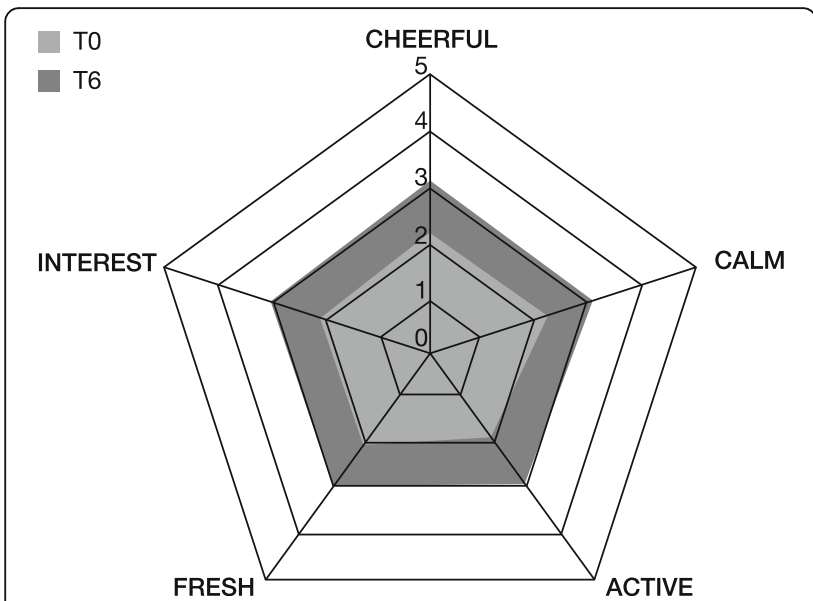

Fig. 6 Individual items of patient wellbeing according to WHO-5 wellbeing index. Cheerful: "I have felt cheerful and in good spirits", calm: "I have felt calm and relaxed", active: "I have felt active and vigorous", fresh: "I woke up feeling fresh and rested", interest: "My daily life has been filled with things that interest me"

TRAEs affected less than $5 \%$ of the patients, except "medication taken at an inappropriate time" $(n=60$, 24.8\%). In these cases, oral aripiprazole was often stopped earlier than recommended ( $<14$ days $)$ after AOM had been initiated. Common TRAEs as well as weight changes and extrapyramidal symptoms are reported in [27]. Only a few TRAEs occurred.

\section{Discussion}

This non-interventional study was conducted to examine whether the positive effects of AOM treatment that have been previously reported in randomized controlled trials $[15,19,20]$ could be replicated in and extended to a naturalistic setting with predominantly stable patients treated with oral aripiprazole before enrollment in the study [27]. Here, we report the outcomes of the GAF rating scale and the WHO-5 questionnaires that were used to assess patient functioning and wellbeing, as well as other outcomes that are relevant for the patient's perspective on the treatment. The main findings were that both GAF and WHO-5 improved significantly and early in predominantly stable patients after switching from oral aripiprazole to $\mathrm{AOM}$ treatment.

At baseline, patients had a mean GAF value of 47.0 (SD: 13.9), indicating that they showed serious symptoms or serious impairment in social and/or occupational functioning. During treatment, the mean value continuously increased with statistically significant changes. Possible cutoff values to define a clinically relevant change have been discussed by Amri et al. [28]. Here, we report numbers for all three suggested thresholds (i.e., $\geq 4, \geq 10$, or $\geq$ 12 points). At $\mathrm{T} 6$, the mean GAF score was 60.2 (SD: 17.0), indicating that the serious symptoms or the difficulties in functioning that the patients had presented with at baseline had become more moderate. These results are consistent with results from a recent non-interventional study in stable Canadian patients treated with AOM that found an improvement from 49 to $61 \mathrm{GAF}$ points within 1 year [31] and other previous findings [18, 32] as well as those of a post-marketing surveillance study of oral aripiprazole, where improvements of 15.8 points on the GAF scale were found [33], and of another naturalistic study that found a 14-point improvement within 6 months [34]. In two randomized controlled trials that studied the effects of AOM, previous improvements in functionality, assessed by the Personal and Social Performance (PSP) scale, could be maintained over long periods of $38-52$ weeks [21]. Paliperidone palmitate LAI also allowed patients with schizophrenia to maintain their improvements on the PSP scale for 15 months [35]. In general, long-acting injectable formulations of second-generation antipsychotics seem to be effective in improving patient functioning and quality of life $[36,37]$.

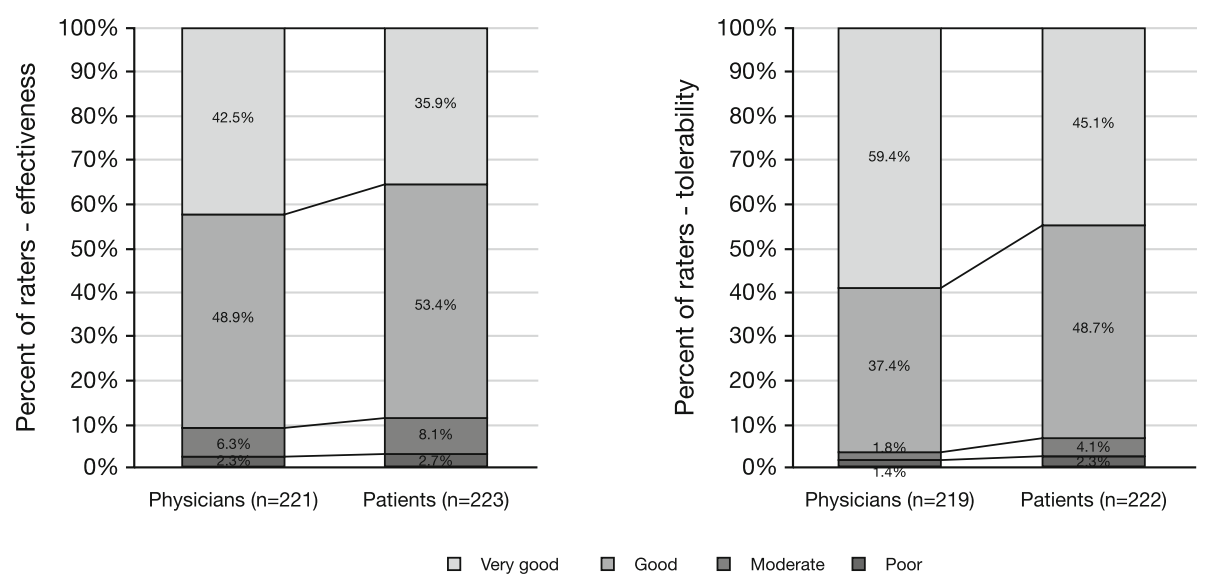

Fig. 7 Assessment of effectiveness and tolerability of AOM treatment by treating physicians and patients 
Changes on the GAF scale are usually accompanied by respective changes on other symptomatic rating scales [38]. This relationship is consistent with our previously reported findings of improvements on BPRS and CGI-Scales in the same sample [27]. In an exploratory subgroup analysis, improvements on the GAF scale appeared more pronounced in younger patients, although this subgroup analysis had less statistical power. A shorter duration of psychotic illness and longer time of administration of a LAI was predictive of functional status in another study [39], which highlights that early use of LAI may improve outcome in those with schizophrenia-spectrum-disorders.

At baseline, the patients had a mean WHO-5 wellbeing index of $10.6( \pm 5.6)$, indicating that they were, on average, in a low mood. WHO- 5 scores of $\leq 12.5$ indicate low mood, while scores of $\leq 7$ indicate likely depression [40]. In our study, patients improved significantly from 10.6 points to a mean of 15.4 , which is comparable to the general population [29]. It is considered that a change of $10 \%$ or more on the scale is clinically relevant [29]. Taken together, all of this suggests that AOM treatment effectively improves patients' wellbeing. These data confirm the impressions recorded by the physicians via the GAF scale and suggest that improvement of patient functioning can lead to increased wellbeing. In general, previous studies found that patient's subjective wellbeing and quality of life increase during antipsychotic treatment, often with superior results during atypical versus typical antipsychotic treatment [41-44].

Again, improvements on wellbeing were more pronounced in younger patients $\leq 35$ years, yet, differences compared to patients $>35$ years old were not statistically significant. An enhanced benefit of AOM treatment in patients aged $\leq 35$ years was also apparent in the QUALIFY study, with marked improvements in the patients` quality of life [15] found in an exploratory, predefined subgroup analysis, which had, however, reduced statistical power. Early start of treatment may help to protect the patients from experiencing repeated episodes, which can cause long-term deterioration in psychosocial functioning and quality of life $[2,9,45]$. Patients, even after a first-episode of psychotic illness, show very high rates of nonadherence $[9,46]$. This non-adherence poses a major risk factor for relapse or experiencing a further psychotic episode. When improving the subjective wellbeing of patients, higher adherence to medication could be expected [24-26], which can protect patients from having further psychotic episodes.

As antagonism of striatal and/or extrastriatal dopamineD2 receptors can cause dysphoric experiences and depression [47-49], despite the high D2 occupancy of aripiprazole, the partial agonist profile at D2 receptors may possibly weaken this effect and can lead to a improved subjective wellbeing [50].
Although the ratings on positive therapeutic effects can differ between patients and physicians, in our study, both patients and physicians had similar ratings regarding the experienced or observed effectiveness of AOM.

Although the tolerability of AOM treatment was rated as "very good" or "good" by the majority of physicians and patients (96.8\% vs. 93.7\%), there were statistically relevant differences in ratings with physicians assuming a better tolerability than patients did. It seems that physicians may overestimate the tolerability of antipsychotic medication. Therefore, although in our study side effects were rare, this finding highlights the importance of asking patients very thoroughly if they are experiencing side effects, because adverse effects are one of the main reasons for nonadherence and treatment discontinuation [8, 51, 52].

The most important reason to switch to AOM treatment was that the adherence to treatment was assured. This result highlights on the one hand the importance of having long-acting injectables as treatment options for patients who have difficulties maintaining consistent drug intake, as maintenance of medication is one of the most important factors of staying relapse-free and relatively stable [4]. On the other hand, it should be emphasized that not only those with a history of non-adherence should be considered for treatment with an LAI, as nonadherence increases over time and as preventing relapses may be even more beneficial than targeting stability after another relapse has occurred [53]. In this study, we showed that even predominantly stable patients have the potential to improve further when switching from oral antipsychotic to LAI treatment. This is consistent with other mirror-image studies in which beneficial effects of LAI antipsychotics were found. Especially those in the first years of their illness will benefit the most from continuous treatment, which may prevent patients from the potential deteriorating effects of functional status and quality of life because of relapses and an ongoing illness process [4]. Furthermore, continuous long-term treatment seems to have a benefit regarding relapse-rates, treatment discontinuation as well as mortality [12, 54].

After the observational study period ended, most patients ( $n=200,82.6 \%)$ continued AOM treatment clinically, underscoring that they experienced the treatment as effective and tolerable and providing further face validity to this result. This finding is also consistent with a recent observational, retrospective, non-interventional study of 261 schizophrenia patients in which $86 \%$ of the patients continued using AOM for $\geq 6$ months [55]. In our study, AOM was ineffective or elicited adverse reactions that led to discontinuation only in a small number of patients.

During the study, only a few TRAEs were recorded. All types of events had already been reported in other AOM studies. A more thorough discussion of TRAEs can be found in [27]. 
An important point of this study was to enroll a naturalistic patient population. Therefore, these predominantly stable patients were only enrolled after the treatment choice had already been made. During oral aripiprazole treatment, most patients had been symptomatically stable, as assessed by the treating psychiatrist (without use of a dedicated rating scale), for a mean duration of 5.9 months (SD 18.2), with 91 patients (39.2\%) being stable for $<1$ month and $28(12.1 \%)$ being not stable at all. Patients in other clinical trials that investigated AOM effectiveness or safety showed similar demographic and epidemiologic data [19, 56-58]. These studies included between 59.4 and $77.4 \%$ of male patients, the mean patient age ranged from 40.1 to 45.2 years, and the mean BMI was between 28.1 and 28.7. The mean age of the first diagnosis ranging between 24.4 years [57] and 28.2 years [20] was also comparable to the one reported here. Therefore, the population analyzed here can be considered characteristic of patients suffering from schizophrenia.

Study limitations include the risk of selection bias (only patients willing to be treated with LAI and AOM medication), the lack of a control or comparator group, the relatively small sample of patients aged $\leq 35$ years, reducing the power for subgroup analyses by age, and the risk of confounding factors due to non-randomization. Therefore, the results can just be interpreted as descriptive. The improvements seen could be due to the switch to the LAI, to improved adherence, or just due to longer time on an antipsychotic medication. Possibly, the same cohort would have improved similarly with an alternative treatment regimen (e.g. a different antipsychotic or even remaining on oral medication). Nevertheless, a recent meta-analysis of uncontrolled, open-label cohort studies suggested that LAI treatment is more efficacious than oral antipsychotic treatment for the prevention of hospitalization in people with schizophrenia [14]. The naturalistic, non-interventional design makes it impossible to identify or exclude possible confounders.

Although a shortcoming of the study is that no placebo group or parallel group was included, observational studies are an important complement to RCTs [59-61] due to their "real life" approach with an increased likelihood of a less biased inclusion of patients with psychotic disorders who might have denied study participation in a (randomized) controlled trial. The efficacy and safety of AOM has already been shown in controlled trials [19, 20, 57, 62]. The present study complements these data by observing a patient cohort that was not as strictly selected as a group for a randomized controlled trial. Therefore, patients with multiple co-morbidities, co-medications, and other risk factors were included. Our data show that AOM is also effective and safe in these patients.

\section{Conclusions}

Our results support previous data collected in randomized controlled trials in a sample followed and treated under routine conditions in clinical practice. Taken together, our findings support that AOM is effective and safe for the outpatient treatment of patients with schizophrenia and that treatment with aripiprazole over time appears to have clinical benefits. Since we had no comparison group our findings have observational character and it can just be assumed why patients improve over the ensuing 6 months. The improvements could be related to a better adherence, more stable plasma levels of the medication and regular contacts with the treatment system.

Patient wellbeing and psychosocial functioning improved during AOM treatment under routine medical practice conditions. Both psychiatrists and patients found AOM treatment effective and tolerable. The positive therapeutic action seemed to be especially pronounced in younger patients, which underlines the need for early and continuous treatment to achieve these treatment outcomes that are important from both a clinician's, family's and, especially, the patient's perspective.

\section{Abbreviations \\ AE: Adverse event; AOM: Aripiprazole once-monthly; BMI: Body Mass Index: BPRS: Brief Psychiatric Rating Scale; CGI-I: Clinical Global Impression - Improvement; CGI-S: Clinical Global Impression - Severity; GAF: Global Assessment of Functioning; ICD: International Classification of Diseases; LAI: Long-acting injectable; LOCF: Last observation carried forward; MedDRA: Medical Dictionary for Regulatory Activities; QUALIFY: Quality of Life with Abilify Maintena ${ }^{\oplus}$; RCT: Randomized controlled trial; SD: Standard deviation; TRAE: Treatment related adverse event; WHO: World Health Organization; WHO-5: WHO-5 Well-Being Index}

\section{Acknowledgements}

The authors thank the physicians contributing to and patients participating in this study, as well as their families and caretakers. We further thank Sandra Höpfner and Anfomed $\mathrm{GmbH}$ for implementation of the study and statistical analysis. We thank Kathrin Lemme (Lundbeck $\mathrm{GmbH}$ ) for support. We also thank Philipp Bauknecht (Dr. Carl GmbH) for medical writing services on behalf of Otsuka Pharma GmbH and Lundbeck $\mathrm{GmbH}$.

\section{Authors' contributions}

KW and WJ designed the study and wrote the protocol. DS, WJ, DL, CC and KW managed the literature searches and analyses. EB undertook the statistical analysis, and DS wrote the first draft of the manuscript. All authors contributed to and have approved the final manuscript.

\section{Funding}

The study was conducted and sponsored by Lundbeck $\mathrm{GmbH}$, Hamburg, Germany, and Otsuka Pharma GmbH, Frankfurt, Germany.

Conception and design of the study was done by Prof. Wiedemann and Dr. Janetzky. Collection of data and analysis of data were performed by an independent CRO. All other authors contributed substantially in interpretation of the data and writing the manuscript.

\section{Availability of data and materials}

The dataset used and/or analyzed during the current study are available from the corresponding author on reasonable request.

\section{Ethics approval and consent to participate}

This study was approved by the Freiburg ethics commission international (Approval number: 014/1336). All patients gave written informed consent. Planning, conduct, and evaluation of the NIS was based on legal 
requirements of the German Medical Products Act (Gesetz über den Verkehr mit Arzneimitteln, §4 [23], sentence 3), the relevant recommendations of the Federal Institute for Drugs and Medical Devices (BfArM), and the Paul-Ehrlich Institute (Empfehlungen des Bundesinstituts für Arzneimittel und Medizinprodukte und des Paul-Ehrlich- Instituts zur Planung, Durchführung und Auswertung von Anwendungsbeobachtungen 2010) as well as the guidelines of the FSA code (Freiwillige Selbstkontrolle für die Arzneimittelindustrie e. V. 2015).

\section{Consent for publication}

Not applicable.

\section{Competing interests}

DS received honoraria for lectures from or has been an advisor to Janssen $\mathrm{GmbH}$, Lundbeck GmbH, Otsuka Pharma GmbH and Takeda. WJ is an employee of Lundbeck GmbH. DL and EB reported no conflicts of interest. CC has been a consultant and/or advisor to or has received honoraria from: Alkermes, Allergan, Gerson Lehrman Group, IntraCellular Therapies, Janssen/ J\&, LB Pharma, Lundbeck, Medavante, Medscape, Neurocrine, Otsuka, Pfizer, ROVI, Sunovion, Takeda, and Teva. He has provided expert testimony for Bristol-Myers Squibb, Janssen, and Otsuka. He served on a Data Safety Monitoring Board for Lundbeck, Pfizer, Roche, and ROVI. He received royalties from UpToDate and grant support from Janssen, Neurocrine and Takeda. He is also a shareholder of LB Pharma. KW has been a consultant and received honoraria for lectures from Janssen $\mathrm{GmbH}$, Lundbeck $\mathrm{GmbH}$ and Otsuka Pharma $\mathrm{GmbH}$.

\section{Author details}

${ }^{1}$ Klinik für Psychiatrie und Psychotherapie, Zentrum für Psychosoziale Medizin, Universitätsklinikum Hamburg-Eppendorf, Martinistrasse 52, 20246 Hamburg, Germany. ${ }^{2}$ Lundbeck GmbH, Ericusspitze 2, 20457 Hamburg, Germany. ${ }^{3}$ ANFOMED GmbH, Röttenbacher Str. 17, 91096 Möhrendorf, Hamburg, Germany. ${ }^{4}$ The Zucker Hillside Hospital, Department of Psychiatry, Hofstra Northwell School of Medicine, Northwell Health, 75-59 263rd St, Glen Oaks, NY 11004, USA. ${ }^{5}$ Department of Psychiatry and Molecular Medicine, Charité Universitätsmedizin, 500 Hofstra Blvd, Hempstead, NY 11549, USA ${ }^{6}$ Department of Child and Adolescent Psychiatry, Augustenburger Platz 1 (Mittelallee 5A), 13353 Berlin, Germany.

Received: 31 May 2019 Accepted: 10 February 2020 Published online: 22 February 2020

\section{References}

1. Kahn RS, Sommer IE, Murray RM, Meyer-Lindenberg A, Weinberger DR Cannon TD, et al. Schizophrenia. Nat Rev Dis Primers. 2015;1:15067.

2. Emsley R, Chiliza B, Asmal L. The evidence for illness progression after relapse in schizophrenia. Schizophr Res. 2013;148(1-3):117-21.

3. Lieberman JA, Jarskog LF, Malaspina D. Preventing clinical deterioration in the course of schizophrenia: the potential for neuroprotection. J Clin Psychiatry. 2006;67(6):983-90.

4. Correll CU, Rubio JM, Kane JM. What is the risk-benefit ratio of long-term antipsychotic treatment in people with schizophrenia? World Psychiatry. 2018;17(2):149-60

5. Valenstein M, Ganoczy D, McCarthy JF, Myra Kim H, Lee TA, Blow FC. Antipsychotic adherence over time among patients receiving treatment for schizophrenia: a retrospective review. J Clin Psychiatry. 2006;67(10):1542-50.

6. Wade M, Tai S, Awenat $Y$, Haddock G. A systematic review of service-user reasons for adherence and nonadherence to neuroleptic medication in psychosis. Clin Psychol Rev. 2017;51:75-95.

7. Phan SV. Medication adherence in patients with schizophrenia. Int J Psychiatry Med. 2016;51(2):211-9.

8. Velligan DI, Sajatovic M, Hatch A, Kramata P, Docherty JP. Why do psychiatric patients stop antipsychotic medication? A systematic review of reasons for nonadherence to medication in patients with serious mental illness. Patient Prefer Adherence. 2017:11:449-68.

9. Tiihonen J, Haukka J, Taylor M, Haddad PM, Patel MX, Korhonen P. A nationwide cohort study of oral and depot antipsychotics after first hospitalization for schizophrenia. Am J Psychiatry. 2011;168(6):603-9.

10. Kishimoto T, Nitta M, Borenstein M, Kane JM, Correll CU. Long-acting injectable versus oral antipsychotics in schizophrenia: a systematic review and meta-analysis of mirror-image studies. J Clin Psychiatry. 2013 Oct;74(10): 957-65.
11. Taipale H, Mehtälä J, Tanskanen A, Tiihonen J. Comparative effectiveness of antipsychotic drugs for Rehospitalization in schizophrenia-a Nationwide study with 20-year follow-up. Schizophr Bull. 2018;44(6):1381-7.

12. Taipale H, Mittendorfer-Rutz E, Alexanderson K, Majak M, Mehtälä J, Hoti F, Jedenius E, Enkusson D, Leval A, Sermon J, Tanskanen A, Tiihonen J. Antipsychotics and mortality in a nationwide cohort of 29,823 patients with schizophrenia. Schizophr Res. 2018;197:274-280. https://doi.org/10.1016/j. schres.2017.12.010.

13. Di Lorenzo R, Ferri P, Cameli M, Rovesti S, Piemonte C. Effectiveness of 1year treatment with long-acting formulation of aripiprazole, haloperidol, or paliperidone in patients with schizophrenia: retrospective study in a realworld clinical setting. Neuropsychiatr Dis Treat. 2019;15:183-98.

14. Kishimoto T, Hagi K, Nitta M, Leucht S, Olfson M, Kane JM, et al. Effectiveness of long-acting injectable vs Oral antipsychotics in patients with schizophrenia: a meta-analysis of prospective and retrospective cohort studies. Schizophr Bull. 2018 Apr 6;44(3):603-19.

15. Naber D, Hansen K, Forray C, Baker RA, Sapin C, Beillat M, et al. Qualify: a randomized head-to-head study of aripiprazole once-monthly and paliperidone palmitate in the treatment of schizophrenia. Schizophr Res. 2015;168(1-2):498-504.

16. Naber D, Baker RA, Eramo A, Forray C, Hansen K, Sapin C, et al. Long-term effectiveness of aripiprazole once-monthly for schizophrenia is maintained in the QUALIFY extension study. Schizophr Res. 2018;192:205-10.

17. Potkin SG, Loze J-Y, Forray C, Baker RA, Sapin C, Peters-Strickland T, et al. Multidimensional assessment of functional outcomes in schizophrenia: results from QUALIFY, a head-to-head trial of Aripiprazole once-monthly and Paliperidone Palmitate. Int J Neuropsychopharmacol. 2017;20(1):40-9.

18. Arques-Egea S, Ros-Cucurull E, Iranzo-Tatay C, Parro-Torres C, Palma-Álvarez RF, Castrillo E, et al. 95 differential aspects between schizophrenia treatment approaches: Oral antipsychotics vs Aripiprazole long-acting injectable. CNS Spectr. 2019;24(1):221-2.

19. Kane JM, Sanchez R, Perry PP, Jin N, Johnson BR, Forbes RA, et al. Aripiprazole intramuscular depot as maintenance treatment in patients with schizophrenia: a 52-week, multicenter, randomized, double-blind, placebocontrolled study. J Clin Psychiatry. 2012;73(5):617-24.

20. Fleischhacker WW, Sanchez R, Perry PP, Jin N, Peters-Strickland T, Johnson $B R$, et al. Aripiprazole once-monthly for treatment of schizophrenia: doubleblind, randomised, non-inferiority study. Br J Psychiatry. 2014;205(2):135-44.

21. Fleischhacker WW, Baker RA, Eramo A, Sanchez R, Tsai L-F, Peters-Strickland $T$, et al. Effects of aripiprazole once-monthly on domains of personal and social performance: results from 2 multicenter, randomized, double-blind studies. Schizophr Res. 2014;159(2-3):415-20.

22. Schaub D, Brüne $M$, Bierhoff $H-W$, Juckel G. Comparison of self- and clinician's ratings of personal and social performance in patients with schizophrenia: the role of insight. Psychopathology. 2012;45(2):109-16.

23. Naber D, Moritz S, Lambert M, Pajonk FG, Holzbach R, Mass R, et al. Improvement of schizophrenic patients' subjective well-being under atypical antipsychotic drugs. Schizophr Res. 2001;50(1-2):79-88.

24. Karow A, Wittmann L, Schöttle D, Schäfer I, Lambert M. The assessment of quality of life in clinical practice in patients with schizophrenia. Dialogues Clin Neurosci. 2014;16(2):185-95.

25. Priebe $S$, Gruyters T, Heinze M, Hoffmann C, Jäkel A. Subjective evaluation criteria in psychiatric care--methods of assessment for research and general practice. Psychiatr Prax. 1995;22(4):140-4.

26. Ruggeri M, Nosè M, Bonetto C, Cristofalo D, Lasalvia A, Salvi G, et al. Changes and predictors of change in objective and subjective quality of life: multiwave follow-up study in community psychiatric practice. $\mathrm{Br}$ J Psychiatry. 2005;187:121-30.

27. Schöttle D, Janetzky W, Luedecke D, Beck E, Correll CU, Wiedemann K Effectiveness of aripiprazole once-monthly in schizophrenia patients pretreated with oral aripiprazole: a 6-month, real-life non-interventional study. BMC Psychiatry. 2018;18(1):365.

28. Amri I, Millier A, Toumi M. Minimum clinically important difference in the global assessment functioning in patients with schizophrenia. Value Health. 2014;17(7):A765-6

29. Topp CW, Østergaard SD, Søndergaard S, Bech P. The WHO-5 well-being index a systematic review of the literature. Psychother Psychosom. 2015;84(3):167-76.

30. Bhapkar VP. A note on the equivalence of two test criteria for hypotheses in categorical data. J Am Stat Assoc. 1966;61(313):228.

31. Mustafa S, Bougie J, Miguelez M, Clerzius G, Rampakakis E, Proulx J, et al. Real-life assessment of aripiprazole monthly (Abilify Maintena) in 
schizophrenia: a Canadian naturalistic non-interventional prospective cohort study. BMC Psychiatry. 2019;19(1):114

32. de Diego BOP G, SLR G. 64 Aripiprazole Long-acting Injectable in Schizophrenia. An 18-month Follow-up and Mirror-image Study. CNS Spectr. 2019;24(1):209-10.

33. Messer T, Schmauß M, Spevakne-Goeroecs T, Kungel M, Ebrecht M, Werner C, et al. Clinical use of aripiprazole in patients with schizophrenia: a real-life setting results from the German Postmarketing surveillance study. World J Biol Psychiatry. 2010;11(2-2):231-8.

34. Christensen AF, Poulsen J, Nielsen CT, Bork B, Christensen A, Christensen M. Patients with schizophrenia treated with aripiprazole, a multicentre naturalistic study. Acta Psychiatr Scand. 2006;113(2):148-53.

35. Fu DJ, Turkoz I, Walling D, Lindenmayer JP, Schooler NR, Alphs L. Paliperidone palmitate once-monthly maintains improvement in functioning domains of the Personal and Social Performance scale compared with placebo in subjects with schizoaffective disorder. Schizophr Res. 2018;192:185-193. https://doi.org/10.1016/j.schres.2017.04.004.

36. Montemagni C, Frieri T, Rocca P. Second-generation long-acting injectable antipsychotics in schizophrenia: patient functioning and quality of life. Neuropsychiatr Dis Treat. 2016;12:917-29.

37. Gómez-Revuelta M, Pelayo-Terán JM, Juncal-Ruiz M, Fernández-Rodríguez M, Vázquez-Bourgon J, Suárez-Pinilla P, et al. 44 real world effectiveness: a 6month naturalistic follow-up study of schizophrenia patients after switching to Aripiprazole monohydrate (AOM) treatment. CNS Spectr. 2019;24(1):199-200.

38. Suzuki T, Uchida H, Sakurai H, Ishizuki T, Tsunoda K, Takeuchi H, et al. Relationships between global assessment of functioning and other rating scales in clinical trials for schizophrenia. Psychiatry Res. 2015;227(2-3):265-9.

39. Girardi P, Del Casale A, Rapinesi C, Kotzalidis GD, Splendori F, Verzura C, et al. Predictive factors of overall functioning improvement in patients with chronic schizophrenia and schizoaffective disorder treated with paliperidone palmitate and aripiprazole monohydrate. Hum Psychopharmacol. 2018;33(3):e2658.

40. Wu S-FV. Rapid screening of psychological well-being of patients with chronic illness: reliability and validity test on WHO-5 and PHQ-9 scales. Depress Res Treat. 2014;2014:239490.

41. Ritsner M, Gibel A, Perelroyzen G, Kurs R, Jabarin M, Ratner Y. Quality of life outcomes of risperidone, olanzapine, and typical antipsychotics among schizophrenia patients treated in routine clinical practice: a naturalistic comparative study. J Clin Psychopharmacol. 2004;24(6):582-91.

42. Mortimer AM, Al-Agib AOA. Quality of life in schizophrenia on conventional versus atypical antipsychotic medication: a comparative cross-sectional study. Int J Soc Psychiatry. 2007;53(2):99-107.

43. Vothknecht S, Schoevers RA, de Haan L. Subjective well-being in schizophrenia as measured with the subjective well-being under neuroleptic treatment scale: a review. Aust N Z J Psychiatry. 2011;45(3):182-92.

44. Awad AG, Voruganti LNP. The impact of newer atypical antipsychotics on patient-reported outcomes in schizophrenia. CNS Drugs. 2013;27(8):625-36.

45. Stahl SM. Long-acting injectable antipsychotics: shall the last be first? CNS Spectr. 2014;19(1):3-5.

46. Kane JM, Kishimoto T, Correll CU. Non-adherence to medication in patients with psychotic disorders: epidemiology, contributing factors and management strategies. World Psychiatry. 2013;12(3):216-26.

47. de Haan L, van Bruggen M, Lavalaye J, Booij J, Dingemans PMAJ, Linszen D. Subjective experience and D2 receptor occupancy in patients with recentonset schizophrenia treated with low-dose olanzapine or haloperidol: a randomized, double-blind study. Am J Psychiatry. 2003;160(2):303-9.

48. de Haan $L$, Lavalaye J, van Bruggen $M$, van Nimwegen $L$, Booij J, van Amelsvoort T, et al. Subjective experience and dopamine D2 receptor occupancy in patients treated with antipsychotics: clinical implications. Can J Psychiatr. 2004;49(5):290-6.

49. Bressan RA, Costa DC, Jones HM, Ell PJ, Pilowsky LS. Typical antipsychotic drugs -- $D(2)$ receptor occupancy and depressive symptoms in schizophrenia. Schizophr Res. 2002;56(1-2):31-6.

50. Mizrahi R, Mamo D, Rusjan P, Graff A, Houle S, Kapur S. The relationship between subjective well-being and dopamine D2 receptors in patients treated with a dopamine partial agonist and full antagonist antipsychotics. Int J Neuropsychopharmacol. 2009;12(5):715-21.

51. Yan T, Greene M, Chang E, Hartry A, Touya M, Broder MS. Medication adherence and discontinuation of Aripiprazole once-monthly $400 \mathrm{mg}$ (AOM 400) versus Oral antipsychotics in patients with schizophrenia or bipolar I disorder: a real-world study using US claims data. Adv Ther. 2018;35(10):1612-25.

52. Taylor DM, Sparshatt A, Amin F, Osborne I, Dzahini O, Hughes G, et al. Aripiprazole long-acting injection - a mirror image study of its effects on hospitalisation at one year. J Psychopharmacol. 2017;31(12):1564-9.
53. Correll CU, Citrome L, Haddad PM, Lauriello J, Olfson M, Calloway SM, et al. The use of long-acting injectable antipsychotics in schizophrenia: evaluating the evidence. J Clin Psychiatry. 2016;77(suppl 3):1-24.

54. Tiihonen J, Mittendorfer-Rutz E, Majak M, Mehtälä J, Hoti F, Jedenius E, et al. Real-world effectiveness of antipsychotic treatments in a Nationwide cohort of 29823 patients with schizophrenia. JAMA Psychiatry. 2017;74(7):686-93.

55. Fagiolini A, Aguglia E, Ballerini A, Callista G, Carpiniello B, Clerici M, et al. Realworld effectiveness of long acting aripiprazole: treatment persistence and its correlates in the Italian clinical practice. Psychiatry Res. 2019;272:698-706.

56. Mallikaarjun S, Kane JM, Bricmont P, McQuade R, Carson W, Sanchez R, et al. Pharmacokinetics, tolerability and safety of aripiprazole once-monthly in adult schizophrenia: an open-label, parallel-arm, multiple-dose study. Schizophr Res. 2013;150(1):281-8.

57. Kane JM, Peters-Strickland T, Baker RA, Hertel P, Eramo A, Jin N, et al. Aripiprazole once-monthly in the acute treatment of schizophrenia: findings from a 12-week, randomized, double-blind, placebo-controlled study. J Clin Psychiatry. 2014;75(11):1254-60.

58. Peters-Strickland T, Baker RA, McQuade RD, Jin N, Eramo A, Perry P, et al. Aripiprazole once-monthly $400 \mathrm{mg}$ for long-term maintenance treatment of schizophrenia: a 52-week open-label study. NPJ Schizophr. 2015;1:15039.

59. Leucht C, Heres S, Kane JM, Kissling W, Davis JM, Leucht S. Oral versus depot antipsychotic drugs for schizophrenia--a critical systematic review and meta-analysis of randomised long-term trials. Schizophr Res. 2011; 127(1-3):83-92.

60. Haddad PM, Tiihonen J, Haukka J, Taylor M, Patel MX, Korhonen P. The place of observational studies in assessing the effectiveness of depot antipsychotics. Schizophr Res. 2011;131(1-3):260-1.

61. Kane JM, Kishimoto T, Correll CU. Assessing the comparative effectiveness of long-acting injectable vs. oral antipsychotic medications in the prevention of relapse provides a case study in comparative effectiveness research in psychiatry. J Clin Epidemiol. 2013;66(8 Suppl):S37-41.

62. Ishigooka J, Nakamura J, Fujii Y, Iwata N, Kishimoto T, lyo M, et al. Efficacy and safety of aripiprazole once-monthly in Asian patients with schizophrenia: a multicenter, randomized, double-blind, non-inferiority study versus oral aripiprazole. Schizophr Res. 2015;161(2-3):421-8.

\section{Publisher's Note}

Springer Nature remains neutral with regard to jurisdictional claims in published maps and institutional affiliations.

\section{Ready to submit your research? Choose BMC and benefit from:}

- fast, convenient online submission

- thorough peer review by experienced researchers in your field

- rapid publication on acceptance

- support for research data, including large and complex data types

- gold Open Access which fosters wider collaboration and increased citations

- maximum visibility for your research: over $100 \mathrm{M}$ website views per year

At BMC, research is always in progress.

Learn more biomedcentral.com/submissions 